\title{
MIRAR AL EXTRANJERO QUE MIRA NUESTRO CINE. CINE ESPAÑOL EN LA CLASE E/LE
}

\author{
Natalia CONTRERAS DE LA LLAVE \\ Universidad de Alicante
}

Nunca miramos sólo una cosa; siempre miramos la relación entre las cosas y nosotros mismos John Berger.

La primera vez que vi en un aula los ojos como platos de un americano llamado Steve, recién llegado de Pennsylvania, mirando a Pepe Isbert vestido de vaquero en Bienvenido Mr. Marshall, supe que valía la pena intentar explicar, descifrar y esclarecerle a él, a Steve, con sus bermudas y su cara de carnívoro saludable, fan de $L a$ guerra de las Galaxias, qué estaba pasando ahí, en el año 1952, en ese pueblo llamado Villar del Campo, perdón, del Río, y qué tenían que ver esos personajes con nosotros, la España de hoy. Y de paso con ellos, los americanos de ayer. Es decir, mi misión era compleja: conseguir ubicar a Steve dentro de un contexto sociocultural dispar, diferente al suyo, hacerlo eficazmente a partir de la lengua meta y de paso que sus conocimientos sobre ésta aumentaran sin bordear la frustración. ¿La película me ayudaba o me dificultaba esta labor? ¿En qué medida? ¿Qué podía hacer yo para que Steve no observara pasivamente el film, para que estuviera sobre aviso de lo que iba a ocurrir, para que la opacidad del sustrato cultural lo fuera un poco menos? Y si sólo hablábamos sobre la película ¿en qué medida mejoraría su competencia comunicativa, las diferentes destrezas, su español, en suma? Y no sólo eso. Lo que yo hiciera no era lo único importante: Steve tenía su propio conocimiento del mundo, sus propias referencias culturales, un bagaje personal sentado ahí, enfrente de mí, un sujeto irrepetible como receptor que yo tenía que tener en cuenta para desempeñar eficazmente mi labor: "Cada sujeto es, de algún modo, irrepetible como productor y receptor de mensajes, desde sus particulares características, lengua/s, cultura/s, es decir, condiciones y circunstancias múltiples y variables" (González Landa, 2004: 106). Intentemos analizar punto por punto todas las cuestiones. 


\section{Una clase de cine español para extranjeros. Más allá de la explotación lingüística}

La película que Steve está viendo no es una actividad didáctica más en el ámbito de una ordinaria clase de español, entreverada de ejercicios gramaticales, actividades comunicativas orales y escritas. El uso de medios y textos audiovisuales en la clase de idiomas es útil y hay multitud de estudios que aportan actividades que complementan los contenidos funcionales en el aula. Pero nosotros estamos hablando de una clase específica de cine español para extranjeros, para estudiantes de E/LE, la clase de Español a través del cine. En los contenidos de la programación de este curso de cine que hemos desarrollado predomina la búsqueda del avance en la competencia intercultural del alumno por encima del contenido puramente lingüístico. Estamos tratando con material real, documentos auténticos dirigidos a un espectador nativo que requieren un conocimiento del entorno sociocultural y en muchos casos históricogeográfico. La necesidad de comprender ese contexto supone el primer gran obstáculo que el profesor debe convertir en una motivación extra para nuestro alumno. Por tanto, el abordaje de la explicación en clase de cine exigiría tener presentes los siguientes objetivos:

\section{Avance en la competencia intercultural y en la adecuación social}

"Una actuación comunicativa es adecuada cuando no sólo es correcta desde el punto de vista lingüístico, sino también desde el punto de vista sociocultural y textual" (Miquel, 2004: 513). ¿De qué hablamos cuando hablamos de referencias culturales? Los símbolos, las creencias, las presuposiciones, las actuaciones... Todas esas "unidades de análisis" (Miquel, 2004: 513) que componen las diferentes culturas tienen un potente y riquísimo documento en las películas de cada país. En el proceso de aprendizaje de una lengua a través de su cine, el estudiante está expuesto a un material enormemente rico en muchos sentidos: gestualidad, diversidad de registros, gran variedad de situaciones cotidianas, por lo que se convierte en una ayuda inestimable en la práctica de adecuación social, es decir, en llegar a conocer cómo actuar correctamente en situaciones de convivencia en la sociedad meta. Sin este sustrato de conocimientos socioculturales, la práctica de una lengua se convierte en un esquema vacío que puede llevar a cometer errores no 
lingüísticos pero sí culturales (como afirma Miquel, más difíciles de "perdonar" por un hablante nativo). Es una información que sabemos que necesitamos, en general, en nuestras clases de E/LE, pero un análisis acertado de un corpus de películas nos ofrece una muestra amplia y diversa de un gran número de contextos que nos vienen dados por multitud de mensajes (imagen y sonido) a los que, de otro modo, tendrían difícil acceso.

\section{Cuestionar lo nuestro para abrirnos a lo nuevo}

Tal y como se ha estudiado en diversas ocasiones, el distanciamiento del propio componente cultural es un elemento fundamental para un correcto análisis del mismo, y un estudiante que no está dispuesto a cuestionar su propia cultura, que se resiste a negarle la universalidad a su comportamiento, difícilmente participará de la sugestiva aventura de aprender los usos y costumbres de una segunda lengua. Dicho de otra manera y entrando en el plano práctico: mostrar una película a un estudiante extranjero significa ponernos todos (incluido el profesor) ante una posición crítica, extrínseca, ante un desplazamiento de nuestro punto de vista habitual que nos servirá para mirarnos "desde fuera", para dibujar mejor nuestra identidad. En el comentario del film en clase, es muy productivo resaltar cómo nuestro carácter como país se pone de relieve en los diálogos, los gestos, el sentido del humor de las películas. "El humor es el arma de los españoles contra lo que les hace sufrir, contra lo que les preocupa, contra la muerte", afirma Almodóvar. Plantear una reflexión sobre las armas culturales con las que cuentan ellos y que podemos observar en el cine (en $s u$ cine) tiene dos resultados sorprendentes y a la vez fructíferos para nuestro objetivo (nunca lo olvidemos) de aprender español:

a) Entran en un segundo nivel de la competencia intercultural, más allá de los horarios de las comidas o los saludos. Los japoneses ponen de relieve más que nunca la importancia del silencio en su sociedad, los estadounidenses sonríen ante la evidencia de la importancia de los héroes individuales en su cultura y, por lo tanto, en su cine (sería impensable una película española donde el presidente del país salvara al mundo convirtiéndose en un héroe de acción al estilo de Harrison Ford, por ejemplo) y ese paso les motiva para la conversación y la reflexión sobre el contraste ideológico y cultural de una manera muy eficaz. En este tipo de cursos, donde la cantidad de información proporcionada nos haría correr el riesgo de convertir la clase en una conferencia, es 
especialmente importante mantener viva la clase interpelando e interactuando con el alumno.

b) El estudiante consigue tejer una sencilla red de conocimientos del mundo que le ponen en relación directa con las otras culturas, llevándole a sentirse parte integradora de un contexto social más amplio. Los soldados americanos vestidos de Reyes Magos, soñados por el campesino de Bienvenido Mr. Marshall, que vienen en un avión del ejército americano para lanzarle un tractor en paracaídas, es una referencia sobre la Navidad en España que será necesario explicar, pero una vez hecha la aclaración, irán más allá y comprenderán la necesidad de ilusionarse de los habitantes de ese pueblo, "la fe en el milagro" como una tendencia universal que nos genera empatía. No nos observarán como algo ajeno y difícil de comprender, sino como una red social de la que ellos, en determinadas situaciones, podrían formar parte. Una actitud receptiva que contribuirá al deseo de aprender y que constataremos en la interacción de los comentarios posteriores al visionado: "La lengua significativa es aquella que transmite al interlocutor algo que realmente tiene significado para él y no se interpreta como una mera práctica lingüística" (Pastor Cesteros, 2004: 159). Este principio, uno de los que rige la mayoría de las clases E/LE de enfoque comunicativo, determina nuestra actitud en una clase de cine para fomentar el desarrollo de la interlengua del alumno.

\section{Herramientas útiles para trabajar sobre el texto fílmico}

La motivación afectiva, tan importante en general para el aprendizaje de una segunda lengua, es un activo en este tipo de clases, pues el alumno se ve involucrado sin darse cuenta en un universo que en un principio le había parecido totalmente ajeno. Por volver a nuestro ejemplo inicial, para empezar deberíamos explicar el título de Bienvenido Mr. Marshall a través de una batería de preguntas a la clase: quién conoce el Plan Marshall, en qué situación estaba EE.UU. en los años cincuenta, qué saben de sus abuelos después de la Segunda Guerra Mundial, de sus padres... Una vez dibujado en clase un contexto histórico-social global a través también de lo particular, y realizado un sondeo de los datos manejados por el alumno, bajamos a lo concreto (el entorno histórico-social de la película en concreto) y será más claro para el estudiante la comprensión del tema que nos ocupa. 
Debemos decir que por la naturaleza del curso, la mayoría de los materiales utilizados son producidos por el profesor, ayudado de artículos, fragmentos audiovisuales, documentales, fotos... Pero, como afirma Amenós (1995: 51) lo más importante es la flexibilidad, adaptarse a las necesidades del grupo y sus esferas de interés. Y esas necesidades vienen dadas fundamentalmente por los siguientes factores:

\section{a) El nivel del alumno}

¿Qué nivel mínimo debe alcanzar el alumno para asistir con éxito a una clase de estas características? Dentro del actual Marco de Referencia Europeo sugeriríamos el B1, heredero del "Nivel Umbral" de Van Eck, esto es, "los contenidos necesarios para alcanzar un nivel mínimo de habilidad comunicativa en una lengua extranjera de forma general" (Pastor Cesteros, 2004: 157). Esto no significa que todos los estudiantes deban ser de este nivel, sino que el alumno B1 será el de nivel más bajo en esa clase. La mezcla de niveles, sin embargo, nos obligará a crear un tipo de material con diversos niveles de dificultad pero realizable para todos, a saber: cuestionarios sobre las películas con preguntas de comprensión, opinión y búsqueda de información; visionado de fragmentos con explotaciones didácticas de diverso tipo (en un posterior apartado propondremos algunos ejemplos prácticos); incluso como experimento esporádico es interesante el visionado de fragmentos/cortometrajes de sus propios países trabajados con métodos deductivos del componente cultural ${ }^{1}$. El uso de cortometrajes españoles en el aula E/LE es muy eficaz y sugestivo principalmente por dos razones: el tiempo limitado de la clase y el hecho de que contengan una historia completa en apenas 10 ó 15 minutos. Esto nos permitirá llevar a cabo una actividad y el visionado completo del texto fílmico en una clase de 60 minutos, además del efecto-sorpresa con el que generalmente cuentan éstos precisamente por su brevedad.

\footnotetext{
${ }^{1}$ Se proyectó un corto sueco (Charlemos un rato de Lukas Moodysson) que suscitó un debate en la lengua meta sobre la incomunicación en la sociedad sueca y sus diferencias con las relaciones socioafectivas en otros países, a partir de la imagen con texto oral en sueco y subtítulos en español (que obligaba a los estudiantes de otras nacionalidades a leer e intentar comprender la unidad breve pero completa del subtítulo).
} 


\section{b) Especificidad cultural y conocimiento del mundo}

Como hemos dicho antes, cada estudiante es único en su bagaje afectivo, ideológico y social, por lo que es interesante realizar una selección extensa y diversificada de los fragmentos y películas que veremos en el aula. Las interpretaciones y reacciones de los alumnos dependen en gran medida de ello y las explotaciones didácticas que se hagan posteriormente al visionado del film sacarán a la luz elementos histórico-políticos, familiares, emocionales bajo prismas muy diversos.

Teniendo en cuenta que a menudo nos topamos con la ausencia de referencias históricas que los alumnos tienen de su propio país y de argumentos culturales generales que podrían ser importantes para la comprensión final de la película, es preciso un tratamiento informativo previo. Además, si seguimos la teoría del input, es esencial que la información y el nivel de ésta no supere en exceso el nivel del alumno (es decir, apenas un determinado grado por encima de sus conocimientos), por lo tanto no lo someteremos a un texto fílmico sin un trabajo anterior al visionado. Y una de las actividades, a mi juicio, más interesantes y útiles en este ámbito son las relacionadas con la búsqueda de información en Internet. Los estudiantes conocen bien la red y saben cómo usarla. Vamos a proponer tres ejemplos de actividades que resumiremos así:

1. Una actividad por grupos, previa al visionado, de búsqueda en la red.

2. Una actividad de interacción con hablantes nativos.

3. Una actividad sobre las relaciones entre cine y literatura basándonos en un fragmento literario y en su correspondiente adaptación cinematográfica.

\section{Propuesta de actividades prácticas para la clase de cine}

ACTIVIDAD A: Los años bárbaros (F. Colomo, 1992)

\begin{tabular}{|l|l|}
\hline Contexto en el que se realiza & $\begin{array}{l}\text { Le precede una clase sobre las } \\
\text { adaptaciones literarias al cine }\end{array}$ \\
\hline Objetivos & $\begin{array}{l}\text { Familiarizarse con el contexto social de } \\
\text { la posguerra española y los conceptos que } \\
\text { verán en la película. } \\
\text { Aproximaciones a las diferencias entre la } \\
\text { historia real, la obra literaria y la película. }\end{array}$ \\
\hline
\end{tabular}

\footnotetext{
${ }^{2}$ No nos extenderemos aquí sobre el tema. Sólo diremos que se explican los diferentes procesos de tratamiento cinematográfico que se les da a los textos fílmicos: qué cosas cambian, por qué, basarse o inspirarse en los textos literarios, etc.
} 


\begin{tabular}{|l|l|}
\hline & $\begin{array}{l}\text { Desarrollo de las destrezas de } \\
\text { comprensión lectora, expresión e } \\
\text { interacción oral a través de textos reales } \\
\text { en Internet. }\end{array}$ \\
\hline Temporalización & \begin{tabular}{l} 
Una sesión de sesenta minutos. \\
\hline Medios necesarios
\end{tabular} \\
\hline $\begin{array}{l}\text { Un aula con ordenadores y acceso a } \\
\text { Internet. }\end{array}$ \\
\hline
\end{tabular}

\section{Desarrollo de la actividad:}

Paso 1

Se divide la clase en tres grupos que buscarán respectivamente una información diferente preparada en forma de cuestionario por el profesor:

\section{Grupo A}

1. La película "Los años bárbaros" está basada en una historia real ¿sabes en cuál?

2. ¿Cómo se llamaban los dos protagonistas REALES de la historia?

3. Uno de los protagonistas escribió una novela basada en su historia ¿cuál es su título?

4. ¿La película es totalmente fiel a los hechos reales?

5. ¿Qué opinan los protagonistas reales de la adaptación?

\section{Grupo B}

1. ¿Qué es el Valle de los Caídos?

2. ¿Quiénes lo construyeron? ¿Cuándo?

3. ¿Qué significado tiene en la actualidad?

4. Uno de los personajes de la película pertenece al SEU ¿sabes qué era?

5. Uno de los personajes femeninos insiste en que su padre fue brigadista: ¿Sabes qué son las Brigadas Internacionales?

\section{Grupo C}

1. ¿En qué año se rodó Los años bárbaros? ¿Qué acontecimientos importantes hubo en España en ese momento?

2. ¿Cómo se llama el director?

3. ¿Qué género de películas suele hacer este director? Nombra algunas.

4. ¿Obtuvo buenas críticas en general? Cita dos críticas: una buena y una mala resumidas en dos frases cada una.

Paso 2

Una vez realizada la búsqueda y recopilada toda la información, los grupos procederán a exponer conjuntamente sus datos al resto de la clase respectivamente. 
Naturalmente, con las acotaciones necesarias del profesor, cuya labor en esta fase de la actividad es básica para fijar, ampliar y delimitar la información encontrada. Tras este proceso, el alumno contará con suficiente información previa para el visionado y mejor comprensión de la película. Es importante destacar aquí que todo material cultural obtenido por el propio alumno es un bien precioso para él, triplica su motivación y, además llega a él de una forma muy similar a la que llega al hablante nativo: a través de diversos medios y es posible que a partir de opiniones a veces divergentes. La labor del profesor, como apuntábamos antes, no será la de elevar sus valoraciones a categoría de norma universal, sino la de concretar y aclarar los datos más confusos para el alumno y, si llega el caso, no tener miedo a la propia subjetividad, pues de esa materia está compuesta nuestra realidad.

\section{ACTIVIDAD B: Las mujeres y el cine en España}

\begin{tabular}{|l|l|}
\hline Contexto en el que se realiza & $\begin{array}{l}\text { Se pretende introducir el cine como reflejo } \\
\text { de los cambios experimentados por la } \\
\text { sociedad española como la } \\
\text { transformación del rol tradicional de la } \\
\text { mujer. }\end{array}$ \\
\hline Objetivos & $\begin{array}{l}\text { Ahondar en el conocimiento de la } \\
\text { sociedad española actual y los procesos de } \\
\text { cambio. } \\
\text { Interaccionar con hablantes nativos. } \\
\text { Desarrollo de la interacción y expresión } \\
\text { oral. }\end{array}$ \\
\hline Temporalización & $\begin{array}{l}\text { Una sesión de 60 minutos. } \\
\text { Medios necesarios }\end{array}$ \\
& $\begin{array}{l}\text { contacto con hablantes nativos como, en } \\
\text { nuestro caso, un campus universitario o } \\
\text { similar. }\end{array}$ \\
\hline
\end{tabular}

\section{Desarrollo de la actividad:}

Paso 1

Se divide la clase en grupos de tres estudiantes y a las siguientes preguntas sobre las mujeres y el cine en España, añaden otras tres del ámbito cinematográfico que les interese hacer a españoles (que casi siempre suelen estar relacionadas con las películas de su país y el conocimiento que los españoles tienen de él). 
a) ¿Conoces alguna directora española de cine?

b) ¿Podrías nombrar alguna película española reciente dirigida por una mujer?

c) ¿Crees que las películas dirigidas por mujeres se diferencian en algo de las dirigidas por hombres (Mi vida sin mí, Te doy mis ojos, Flores de otro mundo...)?

d) ¿Cuál es tu criterio a la hora de elegir una película (tema, director, actor, el cine más cerca de tu casa, género, cine americano...)?

e)

f)

g)

Paso 2

Sale cada grupo fuera de la clase y se les da 15-20 minutos para realizar la encuesta a por lo menos 5 estudiantes españoles.

Paso 3

Al volver al aula, reorganizan los resultados (clasificando las respuestas por criterios de edad o sexo de los encuestados) y exponen las conclusiones al resto de la clase.

A partir de este momento, ya se puede proceder a la introducción de información sobre el tema que nos ocupa (la mujer en el cine español actual) con un conocimiento básico obtenido principalmente por el estudiante ${ }^{3}$.

\section{ACTIVIDAD C: Don Quijote en el cine (nivel mínimo C1 del MRE)}

\begin{tabular}{|c|c|}
\hline Contexto en el que se realiza & $\begin{array}{l}\text { Le precede una clase sobre las relaciones } \\
\text { entre cine y literatura y las influencias } \\
\text { mutuas. }\end{array}$ \\
\hline Objetivos & $\begin{array}{l}\text { Introducir unas nociones básicas sobre la } \\
\text { obra. } \\
\text { Reflexionar sobre las relaciones cine- } \\
\text { literatura. } \\
\text { Ampliar el campo léxico del cine (guión, } \\
\text { escenografía, vestuario, etc.) } \\
\text { Imaginar la puesta en escena de un texto } \\
\text { literario. }\end{array}$ \\
\hline Temporalización & Una sesión de 60-90 minutos. \\
\hline
\end{tabular}

\footnotetext{
${ }^{3}$ El temario de uno de los módulos del curso Español a través del cine está centrado principalmente en la sociedad española actual y los argumentos que reflejan esos cambios en las películas.
} 


\section{Desarrollo de la actividad:}

Paso 1

Se presenta la siguiente relación de textos a los alumnos (previo sondeo de sus conocimientos de la historia de Don Quijote), donde aparece (brevemente) la escena de la muerte de Don Quijote en el libro comparada con la adaptación que se hizo de esos diálogos en el cine. En el cuadro de la izquierda se presentan las partes del texto que se han utilizado en la película en el orden en el que aparecen en la novela. En el texto de la derecha, la adaptación de esos diálogos y el cambio de orden (en los dos últimos cuadros) que se ha hecho de los mismos.

\section{Texto original y orden del mismo}

\section{Diálogos adaptados al cine ${ }^{5}$}

\begin{tabular}{|c|c|}
\hline $\begin{array}{l}\text { 1. Dadme albricias, buenos señores, de } \\
\text { que ya yo no soy don Quijote de la } \\
\text { Mancha, sino Alonso Quijano, a quien } \\
\text { mis constumbres me dieron renombre de } \\
\text { bueno. }\end{array}$ & $\begin{array}{l}\text { 1. Ya no soy Don Quijote de la Mancha, } \\
\text { sino Alonso Quijano, a quien se le dio el } \\
\text { nombre del Bueno. }\end{array}$ \\
\hline $\begin{array}{l}\text { 2. ¿Ahora, señor don Quijote, que } \\
\text { tenemos nueva que está desencantada } \\
\text { Dulcinea sale vuestra merced con eso? }\end{array}$ & $\begin{array}{l}\text { 2. Vamos, vamos ¿qué le sucede a vuesa } \\
\text { merced? Aún le quedan muchas viudas } \\
\text { que socorrer y muchas doncellas que } \\
\text { desencantar. }\end{array}$ \\
\hline $\begin{array}{l}\text { 3. Perdóname, amigo, de la ocasión que te } \\
\text { he dado de parecer loco como yo... }\end{array}$ & $\begin{array}{l}\text { 3. No se muera vuestra merced, mi señor. } \\
\text { Que la mayor locura es morirse sin más } \\
\text { ni más, sin que nadie le mate. Cállate, } \\
\text { Sancho, que nadie te ha preguntado. }\end{array}$ \\
\hline $\begin{array}{l}\text { 4. Ay, no se muera vuestra merced, sino } \\
\text { tome mi consejo y viva muchos años; } \\
\text { porque la mayor locura que puede hacer } \\
\text { un hombre es dejarse morir sin más ni } \\
\text { más, sin que nadie le mate ni otras manos } \\
\text { le acaben que las de la melancolía. }\end{array}$ & $\begin{array}{l}\text { 4. Sancho, hijo, perdóname por hacer que } \\
\text { tú también parezcas loco. }\end{array}$ \\
\hline
\end{tabular}

Paso 2

Tras la lectura en clase y la resolución de dudas de vocabulario, se pide a los alumnos que por parejas, imaginen cómo sería en el cine esa secuencia: qué decorados tendría, qué tipo de música, la luz, el vestuario...

\footnotetext{
${ }^{4}$ Ed. de L. A. Murillo, 1989: 588.

${ }^{5}$ El caballero Don Quijote de Manuel Gutiérrez Aragón.
} 
Paso 3

Se ponen en común todas las ideas y acto seguido se comprueba la secuencia en el DVD, para que tengan ocasión de comprobar en qué habían acertado o imaginado algo distinto.

Paso 4

Se pasa una vez más la secuencia en el DVD y se comprueba el orden y la supresión de algunos párrafos del original:

- Cambios de contenidos semánticos (Cuadro 2).

- Cambios en las categorías temporales, es decir, en el orden de los enunciados (Cuadros 3 y 4$)$.

- Cambios en el proceso estilístico de enunciación, se decir, simplificación del lenguaje (Cuadro 1).

\section{Conclusión}

"La ausencia de cultura banaliza la lengua" afirma Lourdes Miquel (2004: 526) y los profesores de segundas lenguas no podemos esquivar esta cuestión. La mayoría de nosotros lo sabe y así lo aplica, pero defenderemos aquí la pertinencia de llegar a nuestros objetivos finales de aprendizaje de E/LE también a partir de clases específicas de disciplinas que no son las habituales de lengua y cultura a las que estamos acostumbrados. Un curso de Español a través del cine es una tarea continuada sobre un material real y no adaptado especialmente para el extranjero, fomenta la negociación de significados por parte del estudiante, es decir, un constante preguntarse e investigar (en gran parte por él mismo) sobre la lengua viva con la que se enfrenta, haciendo crecer su interés por la sociedad meta. El sustrato cultural está en cambio permanente y pocos elementos como el cine para demostrarlo. Un planteamiento didáctico fundamentado y consistente hace del cine una herramienta educativa que nos dará muchos frutos. Steve existió de verdad, en una clase a la que arrastré a una proyección gratuita en pantalla grande de la película El verdugo (tras haber visto en clase Bienvenido Mr. Marshall). Entró en aquella sala con una sonrisa de resignación, pero al final de aquel curso de cine que duró cuatro meses, expuso un trabajo final sobre el actor Pepe Isbert, lleno de documentación y fotografías, que resultó conmovedor. Él era aparentemente un receptor insólito de aquel tipo de cine, de aquella España de los sesenta, un espectador único que 
ni siquiera Berlanga pudo imaginar en aquellos tiempos: un americano del siglo XXI. Pero había llegado hasta aquí, había cruzado su vida, su conocimiento del mundo, sus emociones y su idioma con el nuestro, y el resultado de todo ello es que volvió a su pueblecito de Pennsylvania sabiendo quién era Pepe Isbert, lo que significa también que conoció, al menos un poco, cómo fue la España de los cincuenta y de los sesenta, cómo había cambiado hasta hoy y, además, podía explicarlo en español. Aprovechemos todas esas películas que quedan por descubrir desde el punto de vista didáctico, nos proporcionarán armas culturales que enriquecerán nuestra visión del mundo y, de paso, la de nuestros numerosos estudiantes. 


\section{BIBLIOGRAFÍA:}

ALMODÓVAR, Pedro, “Almodóvar, la poética de un espejo insobornable”, Litoral. Los poetas en el cine, 2003, pp. 238-243.

AMENÓS PONS, José, “Cine, lengua y cultura” Frecuencia L, 1995, pp.50-52.

, "Cine y literatura para la clase de español", Cuadernos Cervantes, n 4, 2003, pp.115-136.

FLOREZ, Martha, "Estrategias para desarrollar diferentes tipos de textos a través de las películas", redELE, no 1, junio 2004 (www.mec.es/redele/revista1/florez.shtml).

GARNACHO LÓPEZ, Pilar, “¡De cine en la red!”, Cuadernos Cervantes, 2000. (www.cuadernoscervantes.com/multi_39_decine.html).

GONZÁLEZ LANDA, “ Aportaciones de la semiótica” en Sánchez Lobato y Santos Gargallo Ed., Vademécum para la formación de profesores. Enseñar español como L2 y LE, Madrid, SGEL, 2005, pp.105-127.

HERNÁNDEZ, Pilar, "El cine, un recurso didáctico en E/LE. Modelo de explotación de una película (El Bola, España, 2000), Culturele: Cultura e intercultura en la enseñanza del español como lengua extranjera, Universitat de Barcelona. (www.ub.es/filhis/culturele/Pilar_Cervantes.html).

MIQUEL LÓPEZ, Lourdes, "La subcompetencia sociocultural" en Sánchez Lobato y Santos Gargallo Ed., Vademécum para la formación de profesores. Enseñar español como L2 y LE, Madrid, SGEL, 2005, pp. 511-533.

PASTOR CESTEROS, Susana, Aprendizaje de Segundas Lenguas. Lingüística aplicada a la enseñanza de los idiomas, Alicante, Ed. Universidad de Alicante, 2004. 
"El cine en la enseñanza y aprendizaje del español como lengua extranjera", Simposio Didáctica de lengua y cultura, La Coruña, Universidad de la Coruña, 1993, pp. 343-349.

ZAMORA PINEL, Fausto, "Aplicación del cine a la clase de E/LE", Cuadernos Cervantes, $\mathrm{n}^{\mathrm{o}}$ 33, año VII, 2001, pp. 32-36. 